OPEN ACCESS

Edited by:

Lu Yang,

Sichuan University, China

Reviewed by:

Bin Xu,

Shanghai Ninth People's Hospital,

China

Jiandong Zhou,

University of Oxford, United Kingdom

${ }^{*}$ Correspondence:

Xian-Tao Zeng

zengxiantao1128@whu.edu.cn; zengxiantao1128@163.com

Xuan-Yi Ren

d2009049@126.com

Specialty section:

This article was submitted to

Genitourinary Oncology,

a section of the journal

Frontiers in Oncology

Received: 18 October 2021

Accepted: 28 December 2021

Published: 21 January 2022

Citation:

Wang $D-Q$, Shuai J, Zheng $H$, Guo Z-Q, Huang Q, Xu X-F, Li X-D,

$Z i H$, Ming D-J, Ren $X-Y$ and Zeng $X-T$ (2022) Can Routine Blood and Urine

Parameters Reveal Clues

to Detect Bladder Cancer?

A Case-Control Study.

Front. Oncol. 11:796975.

doi: 10.3389/fonc.2021.796975

\section{Can Routine Blood and Urine Parameters Reveal Clues to Detect Bladder Cancer? A Case-Control Study}

\author{
Dan-Qi Wang ${ }^{1,2}$, Juan Shuai ${ }^{3}$, Hang Zheng ${ }^{1}$, Zhong-Qiang Guo ${ }^{1,2}$, Qiao Huang ${ }^{2}$, \\ Xiao-Feng $\mathrm{Xu}^{4}$, Xiao-Dong $\mathrm{Li}^{5,6}$, Hao $\mathrm{Zi}^{1,2,5,6}$, Dao-Jing Ming ${ }^{2,5,6}$, Xuan-Yi Ren ${ }^{7 *}$ \\ and Xian-Tao Zeng ${ }^{1,2 *}$ \\ ${ }^{1}$ Department of Urology, Zhongnan Hospital of Wuhan University, Wuhan, China, ${ }^{2}$ Center for Evidence-Based and \\ Translational Medicine, Zhongnan Hospital of Wuhan University, Wuhan, China, ${ }^{3}$ Department of Geriatrics, Zhongnan \\ Hospital of Wuhan University, Wuhan, China, ${ }^{4}$ Department of Urology, Xianyang Central Hospital, Xianyang, China, \\ ${ }^{5}$ Department of Urology, Huaihe Hospital of Henan University, Kaifeng, China, ${ }^{6}$ Institutes of Evidence-Based Medicine and \\ Knowledge Translation, Henan University, Kaifeng, China, ${ }^{7}$ Department of Urology, Kaifeng Central Hospital, Kaifeng, China
}

Objective: Limited attention has been paid to abnormal blood and urine test results for patients with bladder cancer. The present study aimed to identify whether blood and urine parameters are associated with bladder cancer.

Methods: We used a case-control design and matched each patient with bladder cancer with three healthy controls of the same age and sex. Univariate conditional logistic regression was used to calculate the crude and adjusted odds ratio (OR) and its 95\% $\mathrm{Cl}$. Multivariate conditional logistic regression was performed for confounders adjustment, and Spearman's correlation coefficient was used to assess the correlation between tumor T stages and urine parameters.

Results: Patients with bladder cancer $(n=360)$ and controls $(n=1050)$ were recruited. In the univariate conditional logistic analysis, higher urine $\mathrm{pH}$ was associated with a decreased risk of bladder cancer ( $\mathrm{OR}=0.67,95 \% \mathrm{Cl}=0.57-0.78)$, while higher values of urine protein $(\mathrm{OR}=4.55,95 \% \mathrm{Cl}=3.36-6.15)$, urine glucose $(\mathrm{OR}=1.56,95 \% \mathrm{Cl}=$ 1.18-2.05), and urine occult blood $(\mathrm{OR}=4.27,95 \% \mathrm{Cl}=3.44-5.29)$ were associated with an increased risk of bladder cancer. After adjustment for body mass index, fasting blood glucose, hypertension, red blood cells, white blood cells, lymphocytes, neutrophils, and platelets, significance still remained for urine $\mathrm{pH}(\mathrm{OR}=0.68,95 \% \mathrm{Cl}=0.53-0.88)$, urine protein $(\mathrm{OR}=1.97,95 \% \mathrm{Cl}=1.21-3.19)$, urine glucose $(\mathrm{OR}=2.61,95 \% \mathrm{Cl}=1.39-4.89)$, and urine occult blood $(\mathrm{OR}=3.54,95 \% \mathrm{Cl}=2.73-4.58)$.

Conclusion: This study indicated that lower urine $\mathrm{pH}$ and higher values of urine protein, urine glucose, and urine occult blood might be risk factors for bladder cancer.

Keywords: bladder cancer, urinary biomarkers, diagnosis, blood test, urine test 


\section{INTRODUCTION}

Bladder cancer is the 11th most common cancer globally, with an estimated 550,000 new cases diagnosed in 2018 (1). The incidence rate, mortality rate, and disability-adjusted life-years (DALYs) rate of bladder cancer in men were 3.4 times, 3.3 times, and 3.3 times higher than those in women, respectively (2). Frequently, delayed and incomplete hematuria evaluation has resulted in the diagnosis being too late, especially for women, which has led to worse survival (3). By contrast, bladder cancer treatment is more expensive compared with the treatment of other cancers, and the cost increases with the higher severity of the disease at initial diagnosis (4). Therefore, early detection is crucial for the prognosis and cost-effectiveness of bladder cancer treatment.

Blood-based and urine-based diagnostic biomarkers have been developed to detect potential malignancies; however, none of them have been recommended for the diagnosis and follow-up of bladder cancer in clinical practice guidelines $(5,6)$. For example, although the use of a hematuria dipstick in highrisk populations has been reported, it was not recommended as a screening test because of the low incidence and short lead-time of bladder cancer (7). To improve poor outcomes, a previous casecontrol study identified multiple clinical features, such as visible hematuria, dysuria, and constipation to recognize early symptoms of bladder cancer (8). With consistently emerging technologies, we noticed that routine blood and urine parameters are often neglected when it comes to the recognition of cancer. Therefore, this study aimed to identify whether blood and urine parameters were associated with bladder cancer.

\section{MATERIALS AND METHODS}

\section{Study Design and Subjects}

In this matched case-control study, we enrolled cases from the Bladder Cancer and Benign Prostatic Hyperplasia Study in Chinese Population (BPSC) database (9-11), and all patients provided written informed consent before enrollment. Only patients that were over 18 years old were eligible, and there was no restriction on tumor stage. Patients diagnosed with bladder cancer in situ were also included. The control group consisted of healthy people undergoing health examinations in the Zhongnan Hospital of Wuhan University. This research was reviewed and approved by the Committee for Ethical Affairs of the Zhongnan Hospital of Wuhan University.

\section{Data Collection}

For the case group, data for analysis were obtained from patient records in the BPSC database, from which 431 bladder cancer patients were enrolled. To ensure matches, we randomly selected 4,310 available records from the health examination population. Observations would be excluded from further analysis if there was any missing value in their health information, such as sex; age; weight and height; fasting blood glucose (FBG; mmol/L); diagnosis of hypertension; counts of red blood cells (RBCs; $10^{9}$ / L), white blood cells (WBCs; $\left.10^{9} / \mathrm{L}\right)$, lymphocytes $\left(10^{9} / \mathrm{L}\right)$, neutrophils $\left(10^{9} / \mathrm{L}\right)$, and platelets $\left(10^{9} / \mathrm{L}\right)$; urine $\mathrm{pH}$; urinary protein $(\mathrm{g} / \mathrm{L})$; urinary glucose $(\mathrm{mmol} / \mathrm{L})$; urine occult blood; or tumor stage. Body mass index (BMI) was calculated as weight in kilograms divided by height in square meters $\left(\mathrm{kg} / \mathrm{m}^{2}\right)$. Thereafter, three controls within the same sex and 5-year age categories were selected and matched to each bladder cancer case.

\section{Statistical Analysis}

Categorical variables, such as sex and hypertension, were expressed as counts and percentages, and continuous variables were expressed as the mean and SD. After descriptive statistics analysis, chi-squared tests and t-tests were adopted to identify confounding variables.

Univariate and multivariate conditional logistic regression analyses were conducted to measure the odds ratios (ORs) and 95\% CIs, which examined associations between bladder cancer and urine $\mathrm{pH}$, urinary protein, urinary glucose, and urine occult blood. A purposeful selection strategy of variables was used to build models. Based on biological rationales and reported risk factors of bladder cancer, potential confounding variables were considered and identified from previous comparative results. In addition, Spearman's correlation coefficient was determined to assess correlations between tumor $\mathrm{T}$ stage and urine parameters.

A $p$-value of less than 0.05 was considered statistically significant, and all statistical analyses were accomplished using SAS 9.4 software (SAS, Cary, NC, USA).

\section{RESULTS}

Ultimately, 360 cases and 1,050 matched controls were included (Figure 1). The demographic characteristics of the study participants are shown in Table 1. Statistical differences were observed for BMI and FBG (all $p$-values $<0.001$ ). The proportion of hypertension was different between cases and controls (36.39\% vs. $47.90 \%, p<0.001)$. With regard to routine blood parameters, only lymphocytes were reduced significantly in the case group compared with the control group $(p<0.001)$. The levels of serum total bilirubin, blood urea nitrogen, uric acid, and creatinine in the case group were higher compared with those in the control group (all $p$-values $<0.001$ ).

Table 2 shows the results of univariate conditional logistic regression for urine parameters. The level of urine $\mathrm{pH}$ revealed a strong inverse relationship with the risk of bladder cancer $(\mathrm{OR}=$ $0.67,95 \% \mathrm{CI}=0.57-0.78, p<0.001)$. By contrast, higher levels of urine protein $(\mathrm{OR}=4.55,95 \% \mathrm{CI}=3.36-6.15, p<0.001)$, urine glucose $(\mathrm{OR}=1.56,95 \% \mathrm{CI}=1.18-2.05, p=0.002)$, and urine occult blood $(\mathrm{OR}=4.27,95 \% \mathrm{CI}=3.44-5.29, p<0.001)$ were associated with an increased risk of bladder cancer.

Table 3 shows the results of multivariate conditional logistic regression analysis with confounders adjustment. After adjustment for BMI, FBG, hypertension, RBCs, WBCs, lymphocytes, neutrophils, and platelets in model 2, significant differences remained for urine $\mathrm{pH}(\mathrm{OR}=0.68,95 \% \mathrm{CI}=0.53-0.88)$, urine protein $(\mathrm{OR}=1.97,95 \% \mathrm{CI}=1.21-3.19)$, urine glucose $(\mathrm{OR}=2.61$, $95 \% \mathrm{CI}=1.39-4.89)$, and urine occult blood $(\mathrm{OR}=3.54,95 \% \mathrm{CI}=$ 
Case group

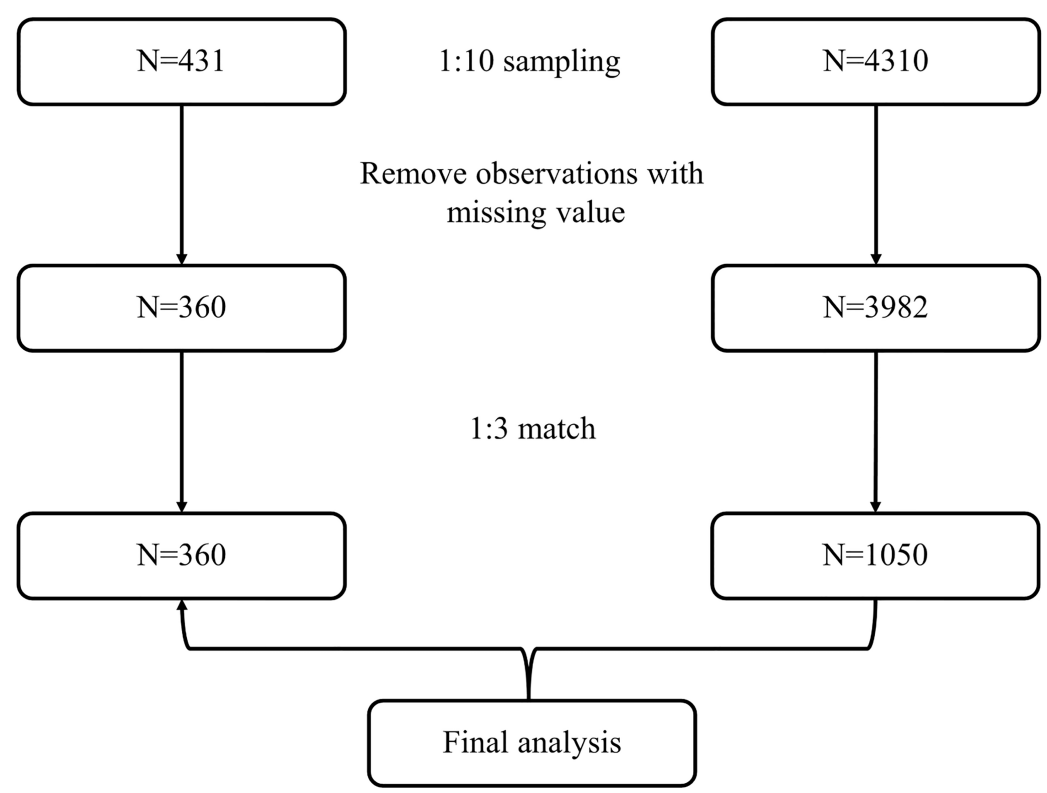

\section{Control group}

FIGURE 1 | Flowchart of the selection of participants.

TABLE 1 | Demographic characteristics and routine blood parameters of the study participants.

\begin{tabular}{|c|c|c|c|c|}
\hline Characteristics & Case group $(\mathrm{N}=360)$ & Control group(N = 1,050) & Chi-squared/t & $p$ \\
\hline Sex & & & - & Matched \\
\hline Male & 289 (80.28\%) & $841(80.10 \%)$ & & \\
\hline Female & $71(19.72 \%)$ & 209 (19.90\%) & & \\
\hline Age (years) & $65.38 \pm 13.11$ & $65.18 \pm 13.18$ & - & Matched \\
\hline BMl $\left(\mathrm{kg} / \mathrm{m}^{2}\right)$ & $23.84 \pm 3.24$ & $24.60 \pm 3.34$ & 3.751 & $<0.001$ \\
\hline FBG (mmol/L) & $5.59 \pm 1.29$ & $5.94 \pm 1.74$ & 4.002 & $<0.001$ \\
\hline Hypertension & 131 (36.39\%) & 503 (47.90\%) & 14.367 & $<0.001$ \\
\hline $\operatorname{RBCs}\left(10^{9} / \mathrm{L}\right)$ & $4.41 \pm 0.53$ & $4.43 \pm 0.44$ & 0.665 & 0.507 \\
\hline WBCs $\left(10^{9} / \mathrm{L}\right)$ & $6.13 \pm 1.79$ & $6.32 \pm 1.64$ & 1.750 & 0.081 \\
\hline Lymphocytes (10/L) & $1.61 \pm 0.56$ & $2.11 \pm 0.62$ & 14.188 & $<0.001$ \\
\hline Neutrophils $\left(10^{9} / \mathrm{L}\right)$ & $4.03 \pm 3.09$ & $3.78 \pm 1.37$ & -1.514 & 0.131 \\
\hline Platelets $\left(10^{9} / \mathrm{L}\right)$ & $193.57 \pm 57.73$ & $191.80 \pm 52.45$ & -0.514 & 0.608 \\
\hline Serum total bilirubin ( $\mu \mathrm{mol} / \mathrm{L})$ & $14.32 \pm 6.56$ & $12.65 \pm 6.24$ & -4.323 & $<0.001$ \\
\hline Blood urea nitrogen $(\mathrm{mmol} / \mathrm{L})$ & $6.06 \pm 2.20$ & $5.19 \pm 1.60$ & -6.861 & $<0.001$ \\
\hline Uric acid $(\mu \mathrm{mol} / \mathrm{L})$ & $352.43 \pm 100.08$ & $304.58 \pm 79.05$ & -8.233 & $<0.001$ \\
\hline Creatinine $(\mu \mathrm{mol} / \mathrm{L})$ & $86.64 \pm 32.03$ & $77.70 \pm 20.17$ & -4.967 & $<0.001$ \\
\hline
\end{tabular}

BMI, body mass index; FBG, fasting blood glucose; RBCs, red blood cells; WBCs, white blood cells.

2.73-4.58). In model 3, the levels of urine protein, urine glucose, and urine occult blood were associated positively with bladder cancer when further adjusted by total bilirubin, blood urea nitrogen, uric acid, and creatinine (all $p$-values $<0.05$ ).

Among the 360 cases included, 62 were at T0/Ta/Tis stage (17.22\%), 201 were at the T1 stage $(55.83 \%), 64$ were at T2/T2a/ T2b stage (17.78\%), 3 were at T3/T3a/T3b stage $(0.83 \%)$, and 30 had missing $\mathrm{T}$ stage data $(8.33 \%)$. The results presented in Table 4 show that the $\mathrm{T}$ stage was associated positively with urine protein and urine occult blood levels (both $p$-values $<0.05$ ). 
TABLE 2 | Univariate conditional logistic regression for urine parameters.

\begin{tabular}{|c|c|c|c|c|}
\hline Exposures & Case group $(\mathrm{N}=360)$ & Control group $(\mathrm{N}=1,050)$ & OR $(95 \% \mathrm{Cl})^{*}$ & $p$ \\
\hline Urine $\mathrm{pH}$ & $5.92 \pm 0.64$ & $6.17 \pm 0.84$ & $0.67(0.57,0.78)$ & $<0.001$ \\
\hline Urine protein (g/L) & $0.47 \pm 0.71$ & $0.09 \pm 0.36$ & $4.55(3.36,6.15)$ & $<0.001$ \\
\hline Urine glucose (mmol/L) & $0.13 \pm 0.61$ & $0.05 \pm 0.30$ & $1.56(1.18,2.05)$ & 0.002 \\
\hline Urine occult blood & $1.30 \pm 1.22$ & $0.18 \pm 0.50$ & $4.27(3.44,5.29)$ & $<0.001$ \\
\hline
\end{tabular}

*OR, odds ratio.

TABLE 3 | Multivariate conditional logistic regression analysis with confounders adjustment.

\begin{tabular}{|c|c|c|c|c|c|c|}
\hline \multirow[t]{2}{*}{ Exposures } & \multicolumn{2}{|c|}{ Model 1} & \multicolumn{2}{|c|}{ Model 2} & \multicolumn{2}{|c|}{ Model 3} \\
\hline & OR $(95 \% \mathrm{Cl})$ & $p$ & OR $(95 \% \mathrm{Cl})$ & $p$ & OR (95\% Cl) & $p$ \\
\hline Urine $\mathrm{pH}$ & $0.66(0.53,0.83)$ & $<0.001$ & $0.68(0.53,0.88)$ & 0.003 & $0.79(0.60,1.04)$ & 0.092 \\
\hline Urine protein (g/L) & $2.11(1.39,3.19)$ & $<0.001$ & $1.97(1.21,3.19)$ & 0.006 & $1.83(1.06,3.16)$ & 0.031 \\
\hline Urine glucose(mmol/L) & $2.43(1.46,4.07)$ & $<0.001$ & $2.61(1.39,4.89)$ & 0.003 & $2.86(1.31,6.26)$ & 0.008 \\
\hline Urine occult blood & $3.47(2.75,4.38)$ & $<0.001$ & $3.54(2.73,4.58)$ & $<0.001$ & $3.67(2.78,4.86)$ & $<0.001$ \\
\hline
\end{tabular}

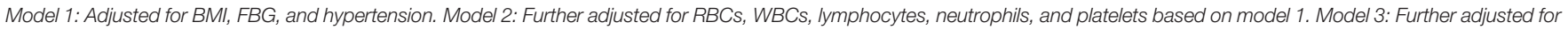
serum total bilirubin, blood urea nitrogen, uric acid, and creatinine based on model 2.

$B M I$, body mass index; FBG, fasting blood glucose; RBCs, red blood cells; WBCs, white blood cells.

TABLE 4 | Spearman's correlation coefficients between T stage and urine parameters.

\begin{tabular}{|c|c|c|c|c|}
\hline Variable & Urine $\mathrm{pH}(p)$ & Urine protein $(p)$ & Urine glucose $(p)$ & Urine occult blood (p) \\
\hline T stage & $0.06(0.26)$ & $0.17(<0.01)$ & $-0.03(0.60)$ & $0.16(<0.01)$ \\
\hline
\end{tabular}

Swedish cohorts, which included 340,000 men, indicated that BMI (hazard ratio $(\mathrm{HR})=1.02,95 \% \mathrm{CI}=0.98-1.08)$ and systolic blood pressure $(\mathrm{HR}=0.98,95 \% \mathrm{CI}=0.94-1.02)$ showed no statistically significant associations with bladder cancer outcomes (13). A prospective pooled cohort study stated that the effects of BMI on bladder cancer varied between males and females. BMI showed a positive association with risk for nonmuscle invasive bladder cancer among men ( $\mathrm{HR}=1.09,95 \%$ $\mathrm{CI}=1.01-1.18$ ) but was inversely associated with bladder cancer risk among women ( $\mathrm{HR}=0.90,95 \% \mathrm{CI}=0.82-0.99)$ (14). Based on the evidence described above, Teleka et al. indicated that estimating bladder cancer risk using BMI values might depend considerably on the composition of the study population in terms of sex and tumor T stage (14). Males made up $80 \%$ of our sample population, and $73.05 \%$ of cases were staged as T0, Ta, Tis, or T1, which could partly explain the divergence between our results and other studies.

Previous studies have reported a positive association between bladder cancer risk and a higher level of FBG (15), and it was not uncommon that patients with diabetes had a higher risk of bladder cancer (16). Nevertheless, in the present study, the FBG of the control group was significantly higher than that of the bladder cancer cases $(p<0.001)$, and the average values of both groups were no more than $6 \mathrm{mmol} / \mathrm{L}$. To support the survival and proliferation of cancer cells, increased glucose uptake is achieved through glucose transporter type 1 (GLUT-1) translocation to the membrane (17), which might account for the decrease in the FBG level in bladder cancer cases. Inhibitors of the sodium-glucose cotransporter-2
(SGLT-2) are increasingly used to treat type 2 diabetes and were reported to be positively associated with the risk of bladder cancer $(\mathrm{OR}=3.97,95 \% \mathrm{CI}=3.39-4.66)$ (18). A study of the metabolic effects of bladder cancer in 22 patients and 10 controls reported a lower glucose clearance accompanied by higher insulin levels, which indicated a state of insulin resistance (19). However, that study was limited by the sample size and the completely different sex balance of the cases and controls. The complex interactions of blood glucose and bladder cancer at different stages remain unclear and require further study.

The complicated interactions between tumors and inflammatory responses (20) have led to hematological inflammation-associated phenomena being used widely to predict the biological behavior of various tumors, including urothelial carcinoma. With regard to bladder cancer, studies have demonstrated the prognostic value of blood cell count, especially the neutrophil-to-lymphocyte ratio (NLR) and the platelet-to-lymphocyte ratio (PLR). For example, it was reported that a higher NLR was associated with an increased risk of disease recurrence and progression in patients with bladder cancer $(21,22)$. Zhao et al. indicated that tumor tissue stimulated the production of neutrophils, which could promote tumor cell proliferation and angiogenesis by releasing cytokines and effector molecules, especially interleukins and the pro-angiogenic vascular endothelial growth factor (23). Meanwhile, a decreased lymphocyte level could weaken adaptive immune responses towards the tumor. The combined effects of these two cellular mechanisms indicated that the NLR reflected the results of antagonism between inflammatory responses and antitumor effects and therefore had a certain 
prognostic value for tumors (23). Blood cell count is routinely tested for hospitalized patients, so it required no additional cost or patient inconvenience (22). Such test results could help clinicians to make targeted treatment plans and follow-up schedules as supplements to imaging and cystoscopy (24). Notably, the antitumor and protumor phenotypes of tumor-associated neutrophils (TANs) are regulated by microenvironmental factors (25-27); therefore, the phenotypes and effects of TANs could vary in different histological types of bladder cancer (28).

According to the results shown in Table 3, the OR values were relatively stable in our three models after adjustment. Our results indicated a consistently positive correlation between lower urine $\mathrm{pH}$ and the risk of bladder cancer, except in model 3, in which uric acid was adjusted. According to previous studies, the independent effects of urine $\mathrm{pH}$ on bladder cancer risk are unclear; however, it was demonstrated that urine $\mathrm{pH}$ could intensify the impact of tobacco exposure (29, 30). Alguacil et al. found that acidic urine (all tested urine $\mathrm{pH}$ values $\leq 6.0$ ) was not associated with the risk of bladder cancer among nonsmokers $(\mathrm{OR}=1.0,95 \% \mathrm{CI}=0.6-1.8)$ but was strongly associated among current smokers $(\mathrm{OR}=2.1,95 \% \mathrm{CI}=1.3-$ 3.2) (30). Moreover, a population with comparable cigarette smoking intensity had an increased risk of bladder cancer with acidic urine, and an interaction existed between consistent acidic urine and heavy smoking $\left(p_{\text {interaction }}=0.024\right)(30)$. High levels of tobacco exposure generate $N$-glucuronidated arylamine carcinogens, which are synthesized in the liver and excreted via the kidneys and bladder. As the medium in which the bladder mucosa is exposed to carcinogens, urine is important in the development of bladder cancer, especially when it carries carcinogens (31). N-Glucuronide conjugates of aromatic amines are relatively inactive at neutral $\mathrm{pH}$ but would be rapidly hydrolyzed to active free aromatic amines and covalently bind to urothelial DNA under acidic conditions (30, 32). For instance, $50 \%$ of the $\mathrm{N}$-glucuronides of benzidine were hydrolyzed after $5 \mathrm{~min}$ at $\mathrm{pH}$ 5.3, $25 \mathrm{~min}$ at $\mathrm{pH}$ 6.3, and $140 \mathrm{~min}$ at $\mathrm{pH} 7.4$ (33). Rothman et al. studied urine samples from Indian workers who were exposed to benzidine occupationally (34), and urine $\mathrm{pH}$ was found to have an inverse correlation with the proportion of free benzidine and associated metabolites $(p<$ 0.001 ). In exfoliated urothelial cells, workers with urine $\mathrm{pH}<6.0$ had 10-fold higher levels of DNA adducts than those with urine $\mathrm{pH} \geq 7.0$ ( $p=0.0037)$ (34). In summary, acidic urine could facilitate the process of carcinogen activation and tumorigenesis. For a population exposed to aromatic amines occupationally or through smoking, low urine $\mathrm{pH}$ could be a particularly important risk factor for bladder cancer (29).

As shown in Table 3, urine occult blood was strongly associated with the risk of bladder cancer, with OR values ranging from 3.47 to 3.67 in models 1,2 , and 3 (all $p$-values $<0.001$ ). Meanwhile, a significant correlation was observed between $\mathrm{T}$ stages and urine parameters $(p<0.01)$ (Table 4), which indicated invasive tumor biological behavior. As the most common symptom of bladder cancer, sometimes the only one, hematuria could be a sign of underlying urological malignancy. It is strongly recommended for patients with symptoms suggestive of bladder cancer to undergo a cystoscopy, which cannot be replaced by cytology or any other noninvasive test in the diagnosis of bladder cancer (7). However, according to a retrospective study, only 25 (1.2\%) among 2,118 patients were diagnosed with bladder cancer using cystoscopy for asymptomatic microscopic hematuria (35). Given that cystoscopy is an invasive and expensive test procedure, its poor detection rate has limited the application of hematuria as a screening test for bladder cancer (35). Two directions were explored to resolve this contradiction. One was to develop non-invasive screening tests in high-risk populations (36) that meet the ASSURED criteria (Affordable, Sensitive, Specific, User-friendly, Rapid, Equipment free, and Deliverable) framed by the WHO. The other was to identify more clinical features associated with bladder cancer, which were used to build accurate prediction models for the diagnosis and prognosis of bladder cancer. Both directions tried to avoid suffering and costly evaluations in relatively low-risk populations (37).

The present study had some limitations. The practical benefit of each independent parameter was confined. However, we failed to build predictive models because of limited data. Based on multiple clinical features, further studies could use a nomogram to predict the occurrence of bladder cancer cases with high accuracy. Besides, we did not conduct subgroup analysis; therefore, the effects of smoking and sex remain unknown.

\section{CONCLUSION}

In this study, we identified and interpreted significant associations between bladder cancer and certain blood and urine parameters. Urine $\mathrm{pH}$, urine protein, urine glucose, and urine occult blood were found to be associated with the risk of bladder cancer and remained significant after adjusting for BMI, FBG, hypertension, RBCs, WBCs, lymphocytes, neutrophils, and platelets. These parameters might be useful in the early detection of bladder cancer. While NLR and urine occult blood have been widely discussed, urine $\mathrm{pH}$, urine protein, and urine glucose are undervalued. This study provides new insight into routine blood and urine parameters and demonstrated their value in the diagnosis and follow-up of bladder cancer.

\section{DATA AVAILABILITY STATEMENT}

The raw data supporting the conclusions of this article will be made available by the authors, without undue reservation.

\section{ETHICS STATEMENT}

The studies involving human participants were reviewed and approved by the Committee for Ethical Affairs of the Zhongnan Hospital of Wuhan University. The patients/participants 
provided their written informed consent to participate in this study.

\section{AUTHOR CONTRIBUTIONS}

D-QW, X-FX, and X-TZ designed this study. JS, Z-QG, HZh, and D-JM collected the data. X-DL and HZi re-checked the data. $\mathrm{HZi}$ and $\mathrm{QH}$ performed the analysis. D-QW and Z-QG wrote the manuscript. X-YR and X-TZ reviewed the manuscript.

\section{REFERENCES}

1. Bray F, Ferlay J, Soerjomataram I, Siegel RL, Torre LA, Jemal A. Global Cancer Statistics 2018: GLOBOCAN Estimates of Incidence and Mortality Worldwide for 36 Cancers in 185 Countries. CA Cancer J Clin (2018) 68 (6):394-424. doi: 10.3322/caac.21492

2. Zi H, He SH, Leng XY, Xu XF, Huang Q, Weng H, et al. Global, Regional, and National Burden of Kidney, Bladder, and Prostate Cancers and Their Attributable Risk Factors, 1990-2019. Mil Med Res (2021) 8(1):60. doi: 10.1186/s40779-02100354-z

3. Fajkovic H, Halpern JA, Cha EK, Bahadori A, Chromecki TF, Karakiewicz PI, et al. Impact of Gender on Bladder Cancer Incidence, Staging, and Prognosis. World J Urol (2011) 29(4):457-63. doi: 10.1007/s00345-011-0709-9

4. Sloan FA, Yashkin AP, Akushevich I, Inman BA. The Cost to Medicare of Bladder Cancer Care. Eur Urol Oncol (2020) 3(4):515-22. doi: 10.1016/j.euo. 2019.01.015

5. Zhang J, Wang Y, Weng H, Wang D, Han F, Huang Q, et al. Management of non-Muscle-Invasive Bladder Cancer: Quality of Clinical Practice Guidelines and Variations in Recommendations. BMC Cancer (2019) 19(1):1054. doi: 10.1186/s12885-019-6304-y

6. Wang DQ, Huang Q, Huang X, Jin YH, Wang YY, Shi YX, et al. Knowledge of and Compliance With Guidelines in the Management of Non-Muscle Invasive Bladder Cancer: A Survey of Chinese Urologists. Front Oncol (2021) 27:735704(11). doi: 10.3389/fonc.2021.735704

7. Babjuk M, Burger M, Compeírat E, Gontero P, Mostafid AH, Palou J, et al. EAU Guidelines on Non-Muscle-Invasive Bladder Cancer (Tat1 and CIS). Arnhem, The Netherlands: European Association of Urology (2020). Available at: https://uroweb.org/guideline/non-muscle-invasivebladdercancer/.

8. Shephard EA, Stapley S, Neal RD, Rose P, Walter FM, Hamilton WT. Clinical Features of Bladder Cancer in Primary Care. Br J Gen Pract (2012) 62(602): e598-604. doi: 10.3399/bjgp12X654560

9. Zeng XT, Liu TZ, Gong K, He DL, Wang XH. The BPSC: A Prospective Study Investigating the Clinical Effect of Interventional Therapy and the Risk Factors for Bladder Cancer and Benign Prostatic Hyperplasia in Chinese Population. J Evid Based Med (2018) 11(1):64-7. doi: 10.1111/jebm.12290

10. Zeng XT, Weng H, Xiong J, Huang Q, Ma LL, Jin YH, et al. Comparison of Clinical and Physiological Parameters for Benign Prostatic Hyperplasia in Hypertensive and Normotensive Patients. Front Physiol (2018) 9:1330. doi: $10.3389 /$ fphys.2018.01330

11. Zhao MJ, Huang Q, Wang XH, Ren XY, Jin YH, Zeng XT. Comparing Clinical Parameters of Abnormal and Normal Fasting Blood Glucose in Benign Prostatic Hyperplasia Patients. Aging Male (2020) 23(5):655-62. doi: 10.1080/13685538.2019.1570493

12. Li HZ, Zheng RS, Du LB, Zhang SW, Zhu C, Wei WW, et al. [Bladder Cancer Incidence, Mortality and Temporal Trends in China]. Zhonghua zhong liu za zhi [Chinese J oncology] (2021) 43(3):293-8. doi: 10.3760/cma.j.cn11215220200421-00362

13. Teleka S, Jochems SHJ, Häggström C, Wood AM, Järvholm B, OrhoMelander M, et al. Association Between Blood Pressure and BMI With Bladder Cancer Risk and Mortality in 340,000 Men in Three Swedish Cohorts. Cancer Med (2021) 10(4):1431-8. doi: 10.1002/cam4.3721

\section{FUNDING}

This work was supported by the National Key Research and Development Plan of China (Technology helps Economy 2020; 2016YFC0106300), without any financial interest or benefit.

\section{ACKNOWLEDGMENTS}

We are grateful to the patients and workers for completing our study.

14. Teleka S, Häggström C, Nagel G, Bjørge T, Manjer J, Ulmer H, et al. Risk of Bladder Cancer by Disease Severity in Relation to Metabolic Factors and Smoking: A Prospective Pooled Cohort Study of 800,000 Men and Women. Int J Cancer (2018) 143(12):3071-82. doi: 10.1002/ijc.31597

15. Zhan YS, Feng L, Tang SH, Li WG, Xu M, Liu TF, et al. Glucose Metabolism Disorders in Cancer Patients in a Chinese Population. Med Oncol (2010) 27 (2):177-84. doi: 10.1007/s12032-009-9189-9

16. Fang H, Yao B, Yan Y, Xu H, Liu Y, Tang H, et al. Diabetes Mellitus Increases the Risk of Bladder Cancer: An Updated Meta-Analysis of Observational Studies. Diabetes Technol Ther (2013) 15(11):914-22. doi: 10.1089/dia. 2013.0131

17. Massari F, Ciccarese C, Santoni M, Iacovelli R, Mazzucchelli R, Piva F, et al. Metabolic Phenotype of Bladder Cancer. Cancer Treat Rev (2016) 45:46-57. doi: $10.1016 /$ j.ctrv.2016.03.005

18. García M, Arteche-Martinez U, Lertxundi U, Aguirre C. SGLT2 Inhibitors and Bladder Cancer: Analysis of Cases Reported in the European Pharmacovigilance Database. J Clin Pharmacol (2021) 61(2):187-92. doi: $10.1002 /$ jcph.1722

19. Lattermann R, Geisser W, Georgieff M, Wachter U, Goertz A, Gnann R, et al. Integrated Analysis of Glucose, Lipid, and Urea Metabolism in Patients With Bladder Cancer. Impact of Tumor Stage. Nutrition (2003) 19(7-8):589-92. doi: 10.1016/s0899-9007(03)00055-8

20. Yuan S, Fang C, Leng WD, Wu L, Li BH, Wang XH, et al. Oral Microbiota in the Oral-Genitourinary Axis: Identifying Periodontitis as a Potential Risk of Genitourinary Cancers. Mil Med Res (2021) 8(1):54. doi: 10.1186/s40779-02100344-1

21. Vartolomei MD, Porav-Hodade D, Ferro M, Mathieu R, Abufaraj M, Foerster B, et al. Prognostic Role of Pretreatment Neutrophil-to-Lymphocyte Ratio (NLR) in Patients With non-Muscle-Invasive Bladder Cancer (NMIBC): A Systematic Review and Meta-Analysis. Urol Oncol (2018) 36(9):389-99. doi: 10.1016/j.urolonc.2018.05.014

22. Tang X, Cao Y, Liu J, Wang S, Yang Y, Du P. Diagnostic Value of Inflammatory Factors in Pathology of Bladder Cancer Patients. Front Mol Biosci (2020) 7:575483. doi: 10.3389/fmolb.2020.575483

23. Zhao R, Shan J, Nie L, Yang X, Yuan Z, Xu H, et al. The Predictive Value of the Ratio of the Product of Neutrophils and Hemoglobin to Lymphocytes in nonMuscular Invasive Bladder Cancer Patients With Postoperative Recurrence. J Clin Lab Anal (2021) 35(8):e23883. doi: 10.1002/jcla.23883

24. Chen S, Jiang L, Zhang E, Hu S, Wang T, Gao F, et al. A Novel Nomogram Based on Machine Learning-Pathomics Signature and Neutrophil to Lymphocyte Ratio for Survival Prediction of Bladder Cancer Patients. Front Oncol (2021) 11:703033. doi: 10.3389/fonc.2021.703033

25. Fridlender ZG, Sun J, Kim S, Kapoor V, Cheng G, Ling L, et al. Polarization of Tumor-Associated Neutrophil Phenotype by TGF-Beta: "N1" Versus "N2" TAN. Cancer Cell (2009) 16(3):183-94. doi: 10.1016/j.ccr.2009.06.017

26. Yin XH, Jin YH, Cao Y, Wong Y, Weng H, Sun C, et al. Development of a 21miRNA Signature Associated With the Prognosis of Patients With Bladder Cancer. Front Oncol (2019) 9:729. doi: 10.3389/fonc.2019.00729

27. Zeng XT, Liu XP, Liu TZ, Wang XH. The Clinical Significance of COL5A2 in Patients With Bladder Cancer: A Retrospective Analysis of Bladder Cancer Gene Expression Data. Med (Baltimore) (2018) 97(10):e0091. doi: 10.1097/ MD.0000000000010091 
28. Yang L, Li A, Liu F, Zhao Q, Ji S, Zhu W, et al. Immune Profiling Reveals Molecular Classification and Characteristic in Urothelial Bladder Cancer. Front Cell Dev Biol (2021) 9:596484. doi: 10.3389/fcell.2021.596484

29. Wright ME, Michaud DS, Pietinen P, Taylor PR, Virtamo J, Albanes D. Estimated Urine $\mathrm{pH}$ and Bladder Cancer Risk in a Cohort of Male Smokers (Finland). Cancer Causes Control (2005) 16(9):1117-23. doi: 10.1007/s10552-005-0348-9

30. Alguacil J, Kogevinas M, Silverman DT, Malats N, Real FX, García-Closas M, et al. Urinary Ph, Cigarette Smoking and Bladder Cancer Risk. Carcinogenesis (2011) 32(6):843-7. doi: 10.1093/carcin/bgr048

31. Shirai T, Fradet Y, Huland H, Bollack C, Droller M, Janknegt R, et al. The Etiology of Bladder Cancer-are There Any New Clues or Predictors of Behavior? Int J Urol (1995) 2(Suppl 2):64-75. doi: 10.1111/j.1442-2042.1995.tb00481.x

32. Lakshmi VM, Hsu FF, Zenser TV. Transformation and Activation of Benzidine by Oxidants of the Inflammatory Response. Chem Res Toxicol (2003) 16(3):367-74. doi: 10.1021/tx0200966

33. Zenser TV, Lakshmi VM, Davis BB. N-Glucuronidation of Benzidine and its Metabolites. Role in Bladder Cancer. Drug Metab Dispos (1998) 26(9):856-9.

34. Rothman N, Talaska G, Hayes RB, Bhatnagar VK, Bell DA, Lakshmi VM, et al. Acidic Urine $\mathrm{pH}$ is Associated With Elevated Levels of Free Urinary Benzidine and N-Acetylbenzidine and Urothelial Cell DNA Adducts in Exposed Workers. C Cancer Epidemiol Biomarkers Prev (1997) 6(12):1039-42.

35. Gonzalez AN, Lipsky MJ, Li G, Rutman MP, Cooper KL, Weiner DM, et al. The Prevalence of Bladder Cancer During Cystoscopy for Asymptomatic Microscopic Hematuria. Urology (2019) 126:34-8. doi: 10.1016/j.urology. 2019.01.011
36. Acharya AP, Theisen KM, Correa A, Meyyappan T, Apfel A, Sun T, et al. An Inexpensive, Point-Of-Care Urine Test for Bladder Cancer in Patients Undergoing Hematuria Evaluation. Adv Healthc Mater (2017) 6(22):1700808. doi: 10.1002/adhm.201700808

37. Matulewicz RS, Rademaker A, Meeks JJ. A Simplified Nomogram to Assess Risk of Bladder Cancer in Patients With a New Diagnosis of Microscopic Hematuria. Urol Oncol (2020) 38(4):240-6. doi: 10.1016/j.urolonc.2019.12.010

Conflict of Interest: The authors declare that the research was conducted in the absence of any commercial or financial relationships that could be construed as a potential conflict of interest.

Publisher's Note: All claims expressed in this article are solely those of the authors and do not necessarily represent those of their affiliated organizations, or those of the publisher, the editors and the reviewers. Any product that may be evaluated in this article, or claim that may be made by its manufacturer, is not guaranteed or endorsed by the publisher.

Copyright ( 2022 Wang, Shuai, Zheng, Guo, Huang, Xu, Li, Zi, Ming, Ren and Zeng. This is an open-access article distributed under the terms of the Creative Commons Attribution License (CC BY). The use, distribution or reproduction in other forums is permitted, provided the original author(s) and the copyright owner(s) are credited and that the original publication in this journal is cited, in accordance with accepted academic practice. No use, distribution or reproduction is permitted which does not comply with these terms. 